\title{
A RELAÇÃo dos PROFESSORES do ENSINO MÉdio COM O LIVRO DIDÁTICO DE QUÍMICA EM ESCOLAS PÚBLICAS DE ITACOATIARA/AM
}

\author{
THE RELATIONSHIP OF HIGH SCHOOL TEACHERS WITH THE CHEMISTRY TEXTBOOK IN \\ PUBLIC SCHOOLS IN ITACOATIARA/AM
}

LA RELACIÓN DE LOS DOCENTES DE SECUNDARIA CON EL LIBRO DE TEXTO DE QUÍMICA EN LAS ESCUELAS PÚBLICAS DE ITACOATIARA/AM

\author{
Jean Michel dos Santos \\ Menezes \\ (iD) \\ Mestre em Ensino de Química \\ (UFAM) \\ Professor no Instituto de Ciências \\ Exatas e Tecnologia (ICET) da \\ Universidade Federal do \\ Amazonas (UFAM) \\ jeanmichelsm@ufam.edu.br
}

\section{Bárbara Samanta Almeida Pereira \\ (iD) 9}

Graduanda em Licenciatura em Ciências: Química e Biologia na Universidade Federal do

Amazonas (UFAM)

samantabarbara4@gmail.com

\section{Dominique Fernandes de Moura do Carmo \\ (iD) 9}

Doutora em Química (UFAM)

Professora no Instituto de Ciências

Exatas e Tecnologia (ICET) da

Universidade Federal do

Amazonas (UFAM)

dominiquefmc@ufam.edu.br

\begin{abstract}
Resumo
Sendo o Livro Didático um dos principais recursos pedagógicos utilizados pelos professores da Educação Básica, ele apresenta papel fundamental no processo de ensino e aprendizagem em Química. A discussão acerca do uso desse recurso ocupa papel de destaque tanto no debate de políticas públicas voltadas à educação, quanto em pesquisas que visam contribuir com a qualidade da educação científica. Desse modo, objetivou-se analisar a relação dos professores de Química da Educação Básica com o Livro Didático de Química. Os dados foram coletados por meio de um questionário e uma entrevista semiestruturada, nos quais participaram 10 professores de Química atuantes nas escolas públicas de Itacoatiara/AM. Identificou-se que $80 \%$ dos professores possui licenciatura específica em Química, sendo ainda 5 especialistas e 2 mestres. $50 \%$ possui mais de 5 anos de experiência docente. Os professores afirmaram ter dificuldade em trabalhar a contextualização pelo livro didático e demonstraram usar o livro como principal instrumento pedagógico, determinando o currículo e de certa maneira a prática pedagógica desses docentes.
\end{abstract}

Palavras-chave: Livro Didático. Ensino de Química. Recursos Didáticos.

Recebido em: 5 de fevereiro de 2021.

Aprovado em: 19 de junho de 2021.

Como citar esse artigo (ABNT):

MENEZES, Jean Michel dos Santos; PEREIRA, Bárbara Samanta Almeida; CARMO, Dominique Fernandes de Moura do. A relação dos professores do ensino médio com o livro didático de química em escolas públicas de Itacoatiara/AM.

Revista Prática Docente, v. 6, n. 2, e042, 2021. http://doi.org/10.23926/RPD.2021.v6.n2.042.id1010 


\section{Abstract}

As the Didactic Book is one of the main pedagogical resources used by Basic Education teachers, it plays a fundamental role in the teaching and learning process in Chemistry. The discussion about the use of this resource occupies a prominent role both in the debate of public policies aimed at education, and in research aimed at contributing to the quality of scientific education. Thus, the objective was to analyze the relationship of teachers of Basic Education Chemistry with the Chemistry Textbook. The data were collected through a questionnaire and a semi-structured interview, in which 10 Chemistry teachers working in the public schools of Itacoatiara/AM participated. It was identified that $80 \%$ of the teachers have a specific degree in Chemistry, with 5 specialists and 2 masters. 50\% have more than 5 years of teaching experience. Teachers said they had difficulty working with contextualization through the textbook, and demonstrated using the book as the main pedagogical tool, determining the curriculum and, in a way, the teaching practice of these teachers. Keywords: Textbook. Chemistry Teaching. Didactic Resources.

\section{Resumen}

Al ser el Libro Didáctico uno de los principales recursos pedagógicos utilizados por los docentes de Educación Básica, él presenta un papel fundamental en el proceso de enseñanza y aprendizaje en Química. La discusión sobre el uso de este recurso ocupa un lugar destacado tanto en el debate de las políticas públicas orientadas a la educación, como en la investigación orientada a contribuir a la calidad de la educación científica. Así, el objetivo fue analizar la relación de los profesores de Química de Educación Básica con el Libro de Texto de Química. Los datos fueron recolectados mediante un cuestionario y una entrevista semiestructurada, en la que participaron 10 profesores de Química que laboran en las escuelas públicas de Itacoatiara / AM. Se identificó que el $80 \%$ de los docentes tienen un título específico en Química, con 5 especialistas y 2 maestrías. El 50\% tiene más de 5 años de experiencia docente. Los docentes manifestaron tener dificultades para trabajar con la contextualización a través del libro de texto, y demostraron que utilizan el libro como principal herramienta pedagógica, determinando el currículo y, en cierto modo, la práctica docente de estos docentes.

Palabras clave: Libro de Texto. Enseñanza de la Química. Recursos Didácticos. 


\section{INTRODUÇÃo}

O Livro Didático (LD) se apresenta como um importante recurso pedagógico que visa a orientação das sequências didáticas e dos conteúdos a serem ministrados em sala de aula pelos professores. Este recurso é destinado ao processo de aprendizagem, intencionalmente estruturado com o fim de melhorar a eficácia (CHOPPIN, 2004).

Levando em consideração essa funcionalidade pedagógica, alguns pesquisadores destacam que o livro didático assume essencialmente três grandes funções: de informação, de estruturação e organização da aprendizagem, e de guia do aluno no processo de compreensão do mundo exterior (CHOPPIN, 2004; SANTOS; CARNEIRO, 2006; MAIA et al., 2011).

Nesse sentido, o LD é apresentado como guia curricular, orientador da prática docente, por vezes com maior influência sobre as ações dos professores do que os próprios referenciais curriculares e teóricos. Assim, é necessário compreender suas potencialidades, limitações e influência sobre a prática educativa de professores (LOPES, 2005).

Apesar do advento exacerbado e plural das tecnologias de informação voltadas ao campo educacional, ainda se encontram em escolas públicas alunos que não possuem acesso a todo esse avanço tecnológico, porém têm contato com os LDs através das políticas públicas de seleção e distribuição desse recurso. Dessa forma, o LD se mantém como um dos principais meios de contato de professores e estudantes com os modelos conceituais do conhecimento científico (MAIA; VILLANI, 2016).

Atualmente, o LD é um material largamente utilizado e distribuído nas escolas públicas brasileiras, por meio do Programa Nacional do Livro Didático (PNLD). A discussão acerca da qualidade do LD ocupa papel de destaque no debate de políticas públicas voltadas à educação. O PNLD é uma política pública proposta pelo Governo Federal que visa justamente promover esse processo de escolha consciente dos LDs que serão utilizados em sala de aula (BRASIL, 2007).

Além do PNLD, existe também outro programa do Governo Federal criado em 2004, o Programa Nacional do Livro Didático para o Ensino Médio (PNLEM), que prevê a universalização de LD para os alunos do Ensino Médio da rede pública de todo o país, uma vez que, até então, o livro era distribuído somente para o Ensino Fundamental. Todo esse programa prevê que cada aluno tem direito a um exemplar do LD de cada disciplina contemplada na Educação Básica, incluindo a Química. Muitos são os critérios que os livros devem atender para serem aprovados pelo Ministério da Educação (MEC) para que consequentemente 
cheguem as escolas. Alguns dos critérios estabelecidos pela comissão avaliadora para que o Livro Didático de Química (LDQ) seja aprovado, é que este aborde a contextualização, a experimentação e a história da Ciência.

A escolha dos livros é feita por meio do Guia do Livro Didático (GLD), com o qual os professores das escolas públicas podem selecionar os livros de sua preferência para serem trabalhados durante um período de três anos. O GLD oferece aos professores condições para que realizem uma escolha adequada, conforme o projeto político-pedagógico da escola em que atuam e as características da comunidade escolar (HORIKAWA; JARDILINO, 2010).

Desde o processo de escolha do LDQ até a sua utilização em sala de aula, é fundamental que o professor apresente uma leitura crítica que o permita planejar a utilização do LDQ de forma a articular os conteúdos e comportamentos que ele trabalha, a fim de relacionar os conhecimentos presentes no livro e os conhecimentos prévios dos alunos.

Assim, segundo Maia e Villani (2016), apesar de o LDQ se constituir num recurso didático imprescindível para o professor, dando-lhe uma sensação de segurança, por outro lado, pode engessá-lo numa rotina mais tradicional, a ponto de impedir ou, ao menos, dificultar o exercício de sua autonomia e criatividade. É importante refletir sobre a relação do professor com o LDQ, no que diz respeito à expressão de sua singularidade, o que exige que ele identifique elementos que contribuam com sua prática e incentive sua capacidade de ir além do que está expresso no livro, adaptando as estratégias para cada contexto.

Pensando nessas questões, o LDQ tem sido foco temático das pesquisas no Ensino de Química. As temáticas encontradas nesse campo vão desde a relação do livro didático com os indivíduos (professores e alunos), a produção e comercialização desse recurso, até a qualidade gráfica e adequação dos conteúdos (LAJOLO, 1996; LOUGUERCIO; SAMRSLA; DEL PINO, 2001; OTESBELGUE et al., 2013; FARIAS, 2018; MELONI; LOPES, 2020).

Miranda, Pazinato e Braibante (2019), por exemplo, buscaram identificar a visão de Ciência veiculada aos conceitos relacionados às forças intermoleculares nos LDQs. Os dados revelaram que as concepções empirista/indutivista ainda estão presentes na metade dos materiais analisados, o que implica na disseminação de distorções sobre a natureza do conhecimento científico.

$\mathrm{Na}$ pesquisa de Bego et al. (2019) concluiu-se que os LDQs analisados apresentam conteúdo e abordagem bastante adequados, sobretudo a não veiculação de erros graves e à 
diferenciação dos aspectos fenomenológico, teórico-conceitual e representacional do conhecimento químico.

Em relação às percepções do professor com o LDQ, Maia e Villani (2016) apontam que esse recurso é o principal representante do conhecimento científico escolar e tem presença marcante na prática dos professores investigados. Os pesquisadores então elencam quatro patamares da relação do docente com o LD:

1 - Rejeição Direta: os professores que se encontram nesse patamar recusam os materiais instrucionais distribuídos às escolas, pois, em suas concepções estes não são capazes de inserir o aluno na cultura científica;

2 - Demanda Passiva: o professor elabora seu planejamento didático acatando a proposta do LD, quanto ao conteúdo, a sequência ou até mesmo as estratégias apresentadas por ele e tendo pouca possibilidade de avaliar a efetiva adequação da proposta com sua compreensão da situação didática;

3 - Aprendizagem Ativa: o professor reconhece a possibilidade de colaboração dos materiais instrucionais, mesmo mantendo a orientação do LD. O ponto importante dessa colaboração é a presença de um investimento do professor para entender, discutir e avaliar as contribuições dos vários subsídios didáticos, organizando-os de acordo com sua compatibilidade.

4 - Pesquisa Criativa: quando existe a possibilidade de uma autonomia do professor em relação aos materiais instrucionais, no sentido de planejar e executar sua atuação didática de acordo com um roteiro original que procura expressar de forma sistemática uma ideia pedagógica.

Nesse contexto, dada a importância desse recurso no processo de ensino e aprendizagem, objetivou-se analisar a relação dos professores de Química da Educação Básica do município de Itacoatiara/AM com o LDQ, no que se refere ao seu uso em sala de aula.

\section{Percurso Metodológico}

O estudo foi realizado no município de Itacoatiara, localizado na Região Metropolitana de Manaus (aproximadamente a uma distância de $270 \mathrm{~km}$ da capital), no estado do Amazonas. É a terceira cidade mais populosa do estado e possui um total de 15 escolas da rede pública que contemplam o nível médio, sendo 13 escolas distribuídas na zona urbana e 2 localizadas na zona rural. 
A pesquisa teve como participantes 10 professores de Química (codificados de P1 a P10) atuantes nas escolas da rede pública de ensino. É importante destacar que a coleta de dados se deu no início do segundo semestre de 2020, sendo realizada totalmente de maneira remota, utilizando ambiente virtuais, devido à pandemia da Covid-19. Por se tratar de uma pesquisa com seres humanos, esta foi submetida ao Comitê de Ética e Pesquisa (CEP) da Universidade Federal do Amazonas (UFAM), com o número de parecer de aprovação 4.539.819.

O presente estudo apresentou caráter predominantemente qualitativo, ou seja, explorou as características dos indivíduos e cenários que não podem ser facilmente descritos numericamente, pesquisa quantitativa. Conforme descrevem Bogdan e Biklen (2013), a pesquisa qualitativa tem o ambiente natural como sua fonte direta de dados, utilizando principalmente métodos que possibilitam a obtenção de dados descritivos que permitem observar o modo de pensar dos indivíduos pesquisados e se preocupando mais com o processo do que com o produto.

Desse modo, para atingir o objetivo traçado, foram utilizados os seguintes instrumentos de coleta de dados:

1 - Questionário: é definido por Sampieri et al. (2013) como um conjunto de perguntas a respeito de uma ou mais variáveis que serão mensuradas em uma pesquisa, devendo ser coerente com a formulação do problema e a hipótese. O conteúdo das questões que compõem esse instrumento é tão variado quanto os aspectos que mensura, sendo considerados dois tipos de questões: fechadas e abertas.

Segundo Moreira e Caleffe (2008) e Moreira (2016) o questionário é um instrumento muito utilizado nas pesquisas em Educação em Ciências, pois, além da economia de tempo na sua aplicação, alcança vários indivíduos pesquisados ao mesmo tempo, economizando pessoal, obtendo respostas rápidas e precisas. O questionário respondido pelos participantes foi adaptado de Maia et. al. (2011) e Farias (2018), organizado com um total de 10 questões abertas e fechadas, sendo que desse total 6 foram selecionadas para discussão neste presente artigo (Quadro 1). O instrumento foi estruturado e disponibilizado para os participantes por meio de um formulário eletrônico. 
Quadro 1 - Questionário respondido pelos docentes

1) Professor, qual a sua formação?

( ) Licenciatura em Química. ( ) Bacharelado em Química. ( ) Outros. Qual?

2) Você já teve oportunidade de fazer formação continuada?

( ) Não. ( ) Especialização. ( ) Mestrado. ( ) Doutorado. ( ) Outro. Qual?

3) Há quanto tempo atua como professor?

4) Você já participou da escolha do LDQ nas escolas que atua (ou atuou)? ( ) Não. ( ) Sim.

5) Existe dificuldade em se trabalhar com o livro adotado pela escola? ( ) Não. ( ) Sim.

6) Como você procura utilizar o LDQ em suas aulas?

Fonte: Dados da pesquisa.

2 - Entrevista: esta pode ser definida como uma conversa a dois, ou entre vários interlocutores, realizada por iniciativa do entrevistador e sempre dentro de uma finalidade, proporcionando ao entrevistador, verbalmente, informações pertinentes com vistas a um objetivo de pesquisa (MINAYO, 2016; SZYMANSKI, 2018).

Segundo Bauer e Gaskell (2015) as entrevistas possibilitam obter dados básicos para o desenvolvimento e a compreensão das relações entre os sujeitos e seu contexto. Nesse sentido, os roteiros de entrevistas coletam não apenas as informações relevantes, mas também abrirão espaço para novos questionamentos e reflexões surgidos do diálogo durante a entrevista.

Minayo (2016) classifica as entrevistas em: a) sondagem de opinião; b) semiestruturada; c) aberta ou em profundidade; d) focalizada; e) projetiva. Levando em consideração as características de cada tipo, adotou-se para a presente pesquisa a entrevista semiestruturada, na qual o entrevistado tem a possibilidade de discorrer sobre o tema em questão a partir de questões abertas ou fechadas. O roteiro de entrevista utilizado foi adaptado de Maia e Villani (2016), contemplando um total de 6 perguntas abertas, sendo que para o presente trabalho serão apresentados os resultados provenientes de 4 delas (Quadro 2). A entrevista foi realizada de maneira remota e seu registro por meio de áudio.

Quadro 2 - Protocolo de entrevista aplicado aos docentes

Data:_____ Hora:__:

Nome do entrevistado:

1) Houve alguma disciplina na sua formação inicial em que você trabalhou o LDQ?

2) Professor, você conhece ou já ouviu falar sobre o PNLD/PNLEM/GLD? Comente sua resposta.

3) Existe alguma dificuldade em se trabalhar com o livro adotado pela escola? Se sim, quais?

4) Quais critérios você adota para escolher o LDQ para desenvolver suas atividades em sala de aula?

Fonte: Dados da pesquisa.

\section{Resultados e Discussões}

Por meio do questionário foi possível identificar o perfil dos professores com relação à sua formação inicial (Figura 1). Identificou-se que $60 \%$ dos professores são formados no curso 
de Licenciatura em Ciências: Química e Biologia. Este curso é ofertado no Instituto de Ciências Exatas e Tecnologia (ICET), unidade UFAM localizada em Itacoatiara. O curso foi criado em novembro de 2005 com o objetivo de atender a demanda da Educação Básica local, desta forma, os professores contêm a competência e habilidade de lecionar aulas com conteúdo de Ciências, Química e Biologia.

Figura 1 - Formação inicial dos professores participantes

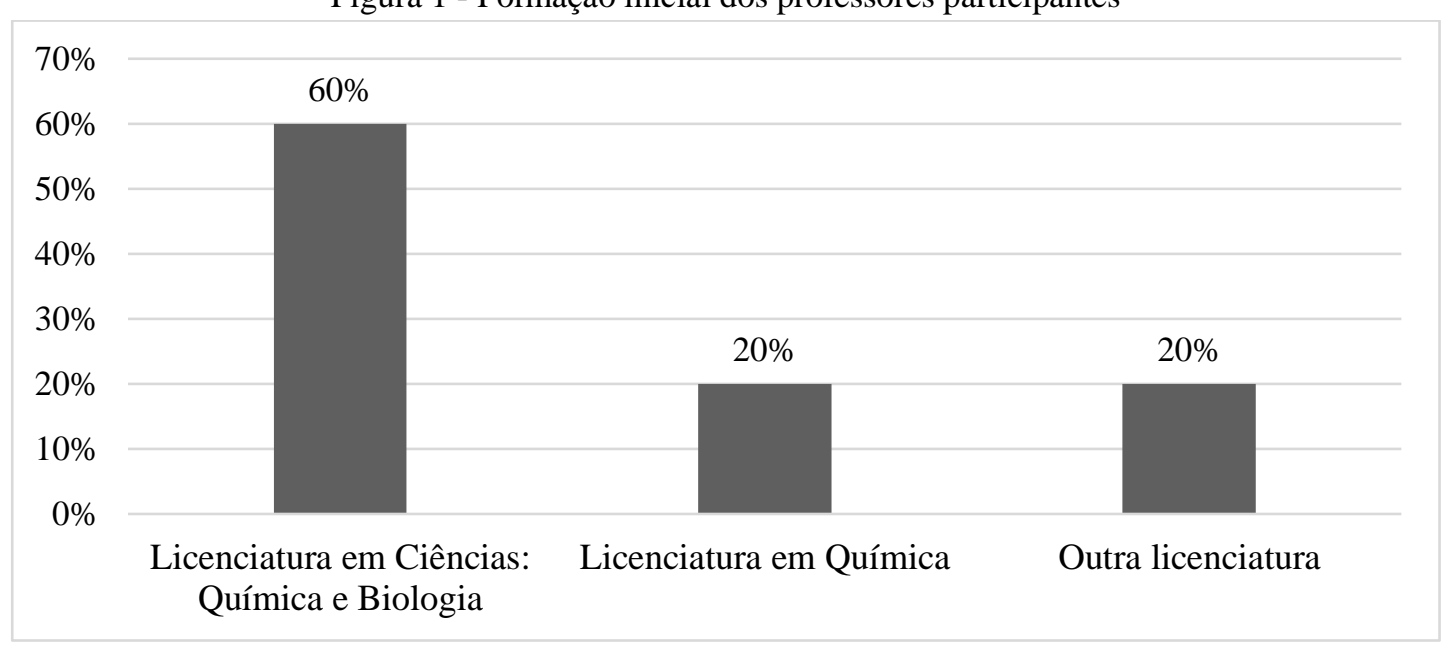

Fonte: Dados da pesquisa.

Foi identificado ainda que $20 \%$ dos professores possuem formação em Licenciatura em Química, em instituições de ensino fora do município e $20 \%$ possui formação em outra área. O fato de $80 \%$ ter uma formação em licenciatura na área é de extrema importância pois estes professores possuem no currículo as disciplinas pedagógicas e as específicas da Química, o que contribui para o processo ensino e aprendizagem. Em algum momento nos cursos de formação de professores é incentivada a leitura e análise do LD da respectiva disciplina, como é possível perceber na fala do professor P2:

“[...] a gente trabalhou o livro didático nas disciplinas de Estágio 1, Estágio 2, e também na Instrumentação para o Ensino da Química [...]” (P2)

Segundo Imbernón (2012), a formação inicial confere o conhecimento profissional básico para o trabalho no campo educacional, o que torna necessário repensar tanto os conteúdos da formação como a metodologia com que estes são trabalhados.

Além da formação inicial, foi investigada a formação continuada dos participantes. A formação continuada tem grande contribuição no processo educacional, pois capacita o professor para ter um melhor desempenho na sua área. Identificou-se que 50\% dos professores possui especialização e $20 \%$ possui formação continuada em nível de mestrado acadêmico. Com o título em mãos, os docentes buscam melhores oportunidades de emprego, almejando 
serem contratados em universidades e institutos federais ou privados, com melhores salários e condições de trabalho.

Para Imbernón (2011) e Bannel et al. (2016) a formação do professor não se dá apenas na formação inicial, mas em uma busca contínua que se torna necessário para mediar os processos constitutivos da cidadania dos alunos. Essa formação continuada deve ajudar o professor a desenvolver um conhecimento profissional que lhe permita avaliar a necessidade potencial e a qualidade da inovação educativa que deve ser introduzida constantemente nas instituições, além de desenvolver habilidades básicas no âmbito das estratégias de ensino em um determinado contexto, do planejamento, da avaliação e da seleção dos recursos didáticos como o livro.

Foi possível identificar também há quanto tempo os participantes da pesquisa exercem a sua profissão (Figura 2). Analisando os dados podemos perceber que $30 \%$ dos professores são iniciantes, atuando no seu primeiro ano de docência. $20 \%$ dos pesquisados exercem a profissão num período compreendido entre 2 a 5 anos. Neste caso pode-se dizer que já possuem uma experiência considerável em sala de aula. Já 30\% dos professores lecionam num período de 5 a 10 anos, e $20 \%$ exercem a docência há mais de 10 anos nas escolas públicas, levando consigo uma boa experiência no seu campo profissional.

Figura 2 - Tempo de docência dos participantes

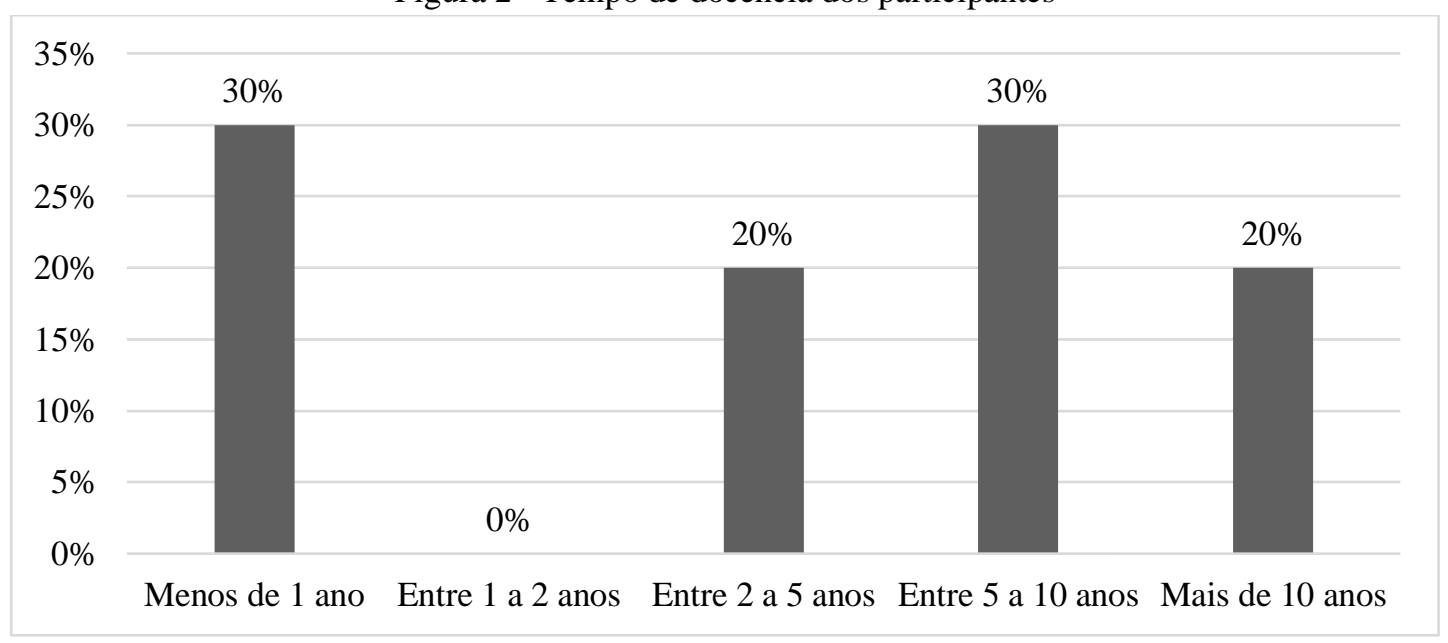

Fonte: Dados da pesquisa.

Segundo Rosa e Mohr (2016) o professor em período inicial do exercício da sua profissão vai aprendendo a escolher e utilizar o LD ao longo de suas atividades profissionais, ou seja, o docente aprende a escolher o LD ao longo de sua vivência no magistério. Na sua pesquisa os autores observaram que quanto maior o tempo de experiência do docente, mais capaz ele se considera para fazer a seleção do LD com que trabalha. 
Ao instigar os professores sobre o GLD e o PNLD percebeu-se que eles já ouviram falar sobre o programa, porém não conhecem detalhes do processo, como é possível perceber na fala de um entrevistado:

“[...] já ouvi falar sim, mas eu não tenho muitas informações, eu sei que é um programa que é para distribuir o livro didático nas escolas 'né', e para estar atualizando esses livros, três em três anos [...]" (P10)

Relacionado à dificuldade de se trabalhar o LDQ, 60\% dos professores afirmaram sentir dificuldade no uso desse recurso nas suas aulas, citando com predominância a contextualização.

“[...] na grande maioria das vezes o livro não cita exemplos regionais, como por exemplo rios e lagos." (P2)

“[...] os exemplos, eles não estão abrangendo a realidade, o cotidiano dos nossos alunos aqui da região [...]" (P5)

Em 2010, o Conselho Nacional de Educação (CNE) promulgou novas Diretrizes Curriculares Nacionais (DCN), ampliando e organizando o conceito de contextualização como sendo a inclusão, a valorização das diferenças e o atendimento à pluralidade e à diversidade cultural resgatando e respeitando as várias manifestações de cada comunidade. Isso também é destacado no texto da Base Nacional Comum Curricular (BNCC) (BRASIL 2018).

A contextualização no LD é um desafio a todas as áreas do conhecimento, no que se refere à sua distribuição nacional, pois não é possível adequar-se plenamente a todos os contextos que envolve um país com tão grandes dimensões e diferentes culturas como é o Brasil (FARIAS, 2018). Desse modo, cabe ao docente analisar o livro que mais se adequa a sua realidade e possibilita a abertura para o trabalho a partir da regionalidade.

É importante salientar a necessidade de o professor refletir que o ensino contextualizado não deve ser confundido apenas com uma simples exemplificação de conceitos com fatos ou situações cotidianas, pois por mais que a contextualização esteja diretamente ligada aos fatos do dia a dia, essa exige um posicionamento de reflexão e problematização no seu desenvolvimento (TIEDEMANN, 2006; BRASIL, 2018).

Em relação ao uso do LDQ no seu processo de ensino, 50\% dos professores relataram que procuram trabalhar todo o conteúdo presente nesse recurso, e 50\% disseram que selecionam aqueles conteúdos que consideram mais importante. Nessas duas percepções podemos identificar dois dos quatro patamares subjetivos de aprendizagem apontados por Villani e Barolli (2000) e reinterpretados por Maia e Villani (2016) no caso da relação do professor com o LD. Os dois patamares foram a "Demanda Passiva" e a "Aprendizagem Ativa". 
A "Demanda Passiva" é a situação análoga àquela na qual o professor elabora seu planejamento didático acatando a proposta do LD, quanto ao conteúdo, à sequência ou até mesmo às estratégias apresentadas por ele e tendo pouca possibilidade de avaliar a efetiva adequação da proposta com sua compreensão da situação didática (MAIA; VILLANI, 2016). Podemos relacionar esse patamar com os professores que trabalham todo o conteúdo no LDQ, seguindo a hierarquização dos conteúdos e a prática dos exercícios.

Turíbio e Silva (2017) também observaram isso na sua pesquisa, no que se refere às práticas pedagógicas. Os pesquisadores constataram que os docentes investigados seguem a mesma sequência dos conteúdos apresentados no livro, ou seja, o livro didático acaba por determinar o currículo e de certa maneira a prática pedagógica dos professores, baseando-se como referencial e instrumental na prática docente.

Já a "Aprendizagem Ativa" é análoga quando o professor reconhece a possibilidade de colaboração dos materiais instrucionais, mesmo mantendo a orientação do LD. O professor entende, discute e avalia as contribuições dos vários subsídios didáticos, organizando-os de acordo com sua compatibilidade (MAIA; VILLANI, 2016). Relacionando com os dados da pesquisa, referimo-nos aos $50 \%$ dos docentes que afirmaram que analisam os conteúdos presentes no LDQ e selecionam o que consideram relevantes e o que pode ser trabalhado nas suas aulas. Por mais que usem esse recurso de maneira complementar na seleção e planejamento dos conteúdos, os professores ainda têm o LDQ como recurso principal devido a este ser, por muitas vezes, o único material que o aluno tem acesso, como observado na resposta dada pelo participante P10.

“[...] eu uso bastante o livro didático atual que os alunos estão tendo no momento, porque a partir do meu planejamento da sequência do assunto em si, eu vou ter maior acesso [...] uso outras bibliografias, principalmente internet, mas eu uso o livro didático porque assim eu vou abranger mais alunos tendo em vista que querendo ou não é o único meio que a gente pode ter algum recurso. É o principal recurso que ainda temos." (P10)

Analisando os dados, além das duas demandas apresentadas, pela fala do docente P6 aspectos de outra demanda foi identificada, a "Rejeição Direta".

“[...] os livros atuais eles vêm muito sucintos, muito técnicos, tudo bem que os alunos já têm que se familiarizar com os textos mais técnicos, mas alguns livros, pelo que observo, eles já subentendem que o aluno sabe alguma coisa [...] é muito difícil o aluno estudar sem o auxílio, sem alguém pra mediar, o livro já subentende que o aluno sabe o assunto na maioria das vezes, ele não vai conseguir estudar sozinho [...]” (P6) 
Essa demanda se refere, no caso da relação dos professores com o LD, que eles tendem a rejeitar o recurso, pois em suas concepções este não é capaz de inserir o aluno na cultura científica (MAIA; VILLANI, 2016).

Por meio dos dados, podemos considerar que os professores que atuam na disciplina de Química apresentam uma certa dependência com o LD, seja por enxergarem esse recurso como único orientador das ações pedagógicas, pois, entre outras coisas, esta ferramenta proporciona segurança e é um facilitador para atuação didática ou por ser este o único recurso possível de ser utilizado na realidade do seu âmbito escolar.

\section{CONSIDERaÇões Finais}

Desse modo, à medida que o LDQ se torna o principal, e às vezes o único instrumento pedagógico em uma escola, deve ser dada uma maior atenção por parte dos professores, seja no processo de escolha, no uso efetivo em sala de aula e na análise das suas potencialidades e limitações.

Avaliando-se as dificuldades enfrentadas no uso do livro, segundo os professores pesquisados, podemos destacar a ausência da contextualização. No que diz respeito ao uso do LDQ no planejamento e ministração das suas aulas, metade dos professores segue o conteúdo desse recurso integralmente, ou seja, o LD acaba por determinar o currículo e de certa maneira a prática pedagógica desses docentes, e a outra metade seleciona o que considera importante e viável e complementa com outras fontes de informação, porém ainda o tem como instrumento principal.

Por mais que hoje o livro não seja mais a única fonte de informação, devido a inúmeros fatores, dentre eles socioeconômicos, ele ainda continua sendo o recurso mais acessível. Dessa maneira, é importante recuperar as funções referencial, documental e pedagógica do LDQ usando-o de modo a explorar as informações nele contidas.

Assim, considera-se que a presente pesquisa pode servir de subsídio para o direcionamento de pesquisas futuras na área de Ensino de Química relativas ao livro didático e no que se refere ao desenvolvimento e organização de outros recursos pedagógicos.

\section{REFERÊNCIAS}

BANNEL, Ralph. Ings; DUARTE, Rosália; CARVALHO, Cristina; PISCHETOLA, Magda; MARAFON, Giovanna; CAMPOS, Gilda Helena. Educação no Século XXI: Cognição, Tecnologias e Aprendizagens. Petrópolis: Vozes; Rio de Janeiro: Editora PUC, 2016. 
BAUER, Martin. W; GASKELL, George. Pesquisa Qualitativa com Texto, Imagem e Som: Um Manual Prático. 13 ${ }^{\mathrm{a}}$ Ed. Petrópolis: Vozes, 2015.

BEGO, Amadeu Moura; SUART JÚNIOR, José Bento; PRADO, Kamila Ferreira; ZULIANI, Silvia Regina Quijadas. Qualidade dos Livros Didáticos de Química Aprovados pelo Programa Nacional do Livro Didático: Análise do Tema Estrutura da Matéria e Reações Químicas. Revista Electrónica de Enseñanza de las Ciencias, v. 18, n. 1, p. 104-123, 2019. Disponível em: http://revistas.educacioneditora.net/index.php/REEC/article/view/365/34. Acesso em: 14/06/2021.

BOGDAN, Robert, BIKLEN, Sari K. Investigação Qualitativa em Educação. Portugal: Porto Editora, 2013.

BRASIL. Ministério da Educação. Secretaria de Educação Básica. Equipamentos e Materiais Didáticos. Brasília: Universidade de Brasília, 2007.

BRASIL. Ministério da Educação. Base Nacional Comum Curricular. Brasília, 2018.

CHOPPIN, Alain. História Dos Livros e das Edições Didáticas: Sobre o Estado da Arte. Educação e Pesquisa, v. 30, n. 3, p. 549-566, 2004. Disponível em: https://www.revistas.usp.br/ep/article/view/27957. Acesso em: 20/01/2021, DOI: https://doi.org/10.1590/S1517-97022004000300012.

FARIAS, Gabriela. Batista. Contextualização, Práticas Educativas e o Livro Didático no Ensino de Química. 2018. 87 f. Manaus: Dissertação (Mestrado em Ensino de Química) Universidade Federal do Amazonas, Manaus, 2018. Disponível em: https://sucupira.capes.gov.br/sucupira/public/consultas/coleta/trabalhoConclusao/viewTrabalh oConclusao.jsf?popup=true\&id_trabalho=7122255. Acesso em: 15/01/2021.

HORIKAWA, Alice Yoko; JARDILINO, José Lima. A Formação de Professores e o Livro Didático: Avaliação e Controle dos Saberes Escolares. Revista Lusófona de Educação, v. 15, n. 15, p. 147-162, 2010. Disponível em:

https://revistas.ulusofona.pt/index.php/rleducacao/article/view/1530. Acesso em: 14/06/2021.

IMBERNÓN, Francisco. Formação Docente e Profissional: Formar-se para a Mudança e a Incerteza. 9a Ed. São Paulo: Cortez, 2011.

IMBERNÓN, Francisco. Inovar o Ensino e a Aprendizagem na Universidade. São Paulo: Cortez, 2012.

LAJOLO, Marisa. Livro didático: Um (quase) Manual de Ensino. Em Aberto, v. 16, n. 69, p. 40-49, 1996. Disponível em:

http://www.emaberto.inep.gov.br/ojs3/index.php/emaberto/article/view/2368. Acesso em: 15/01/2021, DOI: https://doi.org/10.24109/2176-6673.emaberto.16i69.2061.

LOPES, Celi Espasandin; MEIRELLES, Elaine. O Desenvolvimento da Probabilidade e da Estatística. In: XVIII ENCONTRO REGIONAL DE PROFESSORES DE MATEMÁTICA LEM/IMECC/UNICAMP, 2005, Campinas. Anais... Campinas - SP, 2005, p. 1-8. Disponível em: https://www.ime.unicamp.br/erpm2005/anais/m_cur/mc02_b.pdf. Acesso em: $15 / 01 / 2021$. 
LOGUERCIO, Rochele de Quadros; SAMRSLA, Vander Edier Ebling.; DEL PINO, José Cláudio. A Dinâmica de Analisar Livros Didáticos com os Professores de Química. Química Nova, v. 24, n. 4, p. 557-562, 2001. Disponível em:

http://quimicanova.sbq.org.br/detalhe_artigo.asp?id=717. Acesso em: 20/12/2020.

MAIA, Juliana de Oliveira; SÁ, Luciana Passos.; MASSENA, Elisa Prestes; WARTHA, Edson. José. O Livro Didático de Química nas Concepções de Professores do Ensino Médio da Região Sul da Bahia. Química Nova na Escola, v. 33, n. 2, p. 115-124, 2011. Disponível em: http://qnesc.sbq.org.br/online/qnesc33 2/07-PE7110.pdf. Acesso em: 21/01/2021.

MAIA, Juliana de Oliveira; VILLANI, A. A Relação de Professores de Química com o Livro Didático e o Caderno do Professor. Revista Electrónica de Enseñanza de las Ciencias, v. 15, n. 1, p. 121-146, 2016. Disponível em: http://reec.uvigo.es/volumenes/volumen15/REEC_15_1_7_ex969.pdf. Acesso em: 21/01/2021.

MELONI, Reginaldo Alberto; LOPES, Alice Casimiro. Produção de Sentidos pelas Imagens em Livros Didáticos de Química. Ciência \& Educação, v. 26, e20052, 2020. Disponível em: https://doi.org/10.1590/1516-731320200052. Acesso em: 14/06/2021.

MINAYO, Maria Cecília de Souza. Trabalho de Campo: Contexto de Observação, Interação e Descoberta. In: MINAYO, Maria Cecília de Souza; DESLANDES, Suely Ferreira; GOMES, Romeu. Pesquisa Social: Teoria, Método e Criatividade. Petrópolis: Vozes, 2015.

MIRANDA, Ana Carolina Gomes; PAZINATO, Maurícius Selvero; BRAIBANTE, Mara Elisa F. A Visão de Ciência Apresentada em Livros Didáticos de Química na Abordagem de Forças Intermoleculares. Vivências: Revista Eletrônica de Extensão da URI, v. 15, n. 28, p. 23-34, 2019. Dispomível em: http://revistas.uri.br/index.php/vivencias/article/view/10. Acesso: $14 / 06 / 2021$.

MOREIRA, Herivelton., CALEFFE, Luiz. Gonzaga. Metodologia da Pesquisa para o Professor Pesquisador. $2^{\text {a }}$ Ed. Rio de Janeiro: Lamparina, 2008.

MOREIRA, Marco A. Questionário como um Instrumento Auxiliar na Coleta de Dados no Ensino e na Pesquisa em Ensino. In: MASSONI, Neusa T.; MOREIRA, Marco A. Pesquisa Qualitativa em Educação em Ciências: Projetos, Entrevistas, Questionários, Teoria Fundamentada, Redação Científica. São Paulo: Editora Livraria da Física, 2016.

OTESBELGUE, Roseli; SCHRÖDER, Ana Helena; DIAS, Ane Maciel; ALBRECHT, Letícia Daiane; DUBOW, Michele; FERREIRA, Maria. Programa Nacional do Livro Didático e a Análise de Livros Didáticos de Química. In: $33^{\circ}$ Encontro de Debates sobre o Ensino de Química, UNIJUí, 2013. Disponível em: file:///C:/Users/miche/Downloads/2778Texto\%20do\%20artigo-11203-1-10-20131003.pdf. Acesso em 10/01/2021.

ROSA, Marcelo D’Aquino.; MOHR, Adriana. Seleção e Uso do Livro Didático: Um Estudo com Professores de Ciências na Rede de Ensino Municipal de Florianópolis. Revista Ensaio em Educação em Ciências, v. 18, n. 3, p. 97-115, 2016. Disponível em: https://www.scielo.br/pdf/epec/v18n3/1983-2117-epec-18-03-00097.pdf. Acesso 21/01/2021, DOI: https://doi.org/10.1590/1983-21172016180305. 
SAMPIERI, Roberto Hernández; COLLADO, Carlos Fernández; LUCIO, María del Pilar Baptista. Metodologia da Pesquisa. 5 ${ }^{\text {a }}$ Ed. Porto Alegre: Penso, 2013.

SANTOS, Wildson Luiz Pereira; CARNEIRO, Maria Helena da Silva. Livro Didático de Ciências: Fonte de Informação ou Apostila de Exercícios? Contexto e Educação, v. 21, n. 76, p. 201-222, 2006. Disponível em:

https://www.revistas.unijui.edu.br/index.php/contextoeducacao/article/view/1103. Acesso em: 25/01/2021, DOI: https://doi.org/10.21527/2179-1309.2006.76.201-222.

SZYMANSKI, Heloisa. Entrevista Reflexiva: Um Olhar Psicológico sobre a Entrevista em Pesquisa. In: SZYMANSKI, Heloisa.; ALMEIDA, Laurinda Ramalho; PRANDINI, Regina Célia Almeida Rego. A Entrevista na Pesquisa em Educação: A Prática Reflexiva. $5^{\text {a }}$ Ed. Campinas: Autores Associados, 2018.

TIEDEMANN, Peter W.; Conteúdos de Química em Livros Didáticos de Ciências. Educação e Ciência, v. 5, n. 2, p. 15-22, 2006. Disponível em:

https://www.scielo.br/scielo.php?script=sci arttext\&pid=S1516-73131998000200002. Acesso em: 26/01/2021, DOI: https://doi.org/10.1590/S1516-73131998000200002.

TURÍBIO, Solange Ramos Teixeira; SILVA, Adelmo Carvalho. A Influência do Livro Didático na Prática Pedagógica do Professor que Ensina Matemática. Revista Prática Docente, v. 2, n. 2, p. 158-178, 2017. Disponível em:

http://periodicos.cfs.ifmt.edu.br/periodicos/index.php/rpd/article/view/73. Acesso em: 26/01/2021, DOI: https://doi.org/10.23926/RPD.2526-2149.2017.v2.n2.p158-178.id73.

VILLANI, Alberto; BAROLLI, Elisabeth. Interpretando a Aprendizagem nas Salas de Aula de Ciências. In: 23 $3^{\mathrm{a}}$ Reunião Anual da ANPED, 2000, Caxambu. Anais... Caxambu - MG, 2000. Disponível em: http://23reuniao.anped.org.br/textos/0417t.PDF. Acesso em 22/12/2020. 